\title{
A Case Study of Teaching High-level Reflection to Teachers: Dissecting My Failing Journey
}

\author{
Jung-ah Choi \\ Correspondence: Jung-ah Choi, PhD, School of Education, St. Peter's University, Jersey City, NJ, USA.
}

Received: June 9, 2020

Accepted: July 27, 2020

Online Published: July 29, 2020

doi:10.11114/jets.v8i9.4950

URL: https://doi.org/10.11114/jets.v8i9.4950

\begin{abstract}
While the teacher education literature stressed the importance of teachers' reflection for the purpose of their professional growth, very few focus on teacher's personal intellectual growth, intelligent dispositions. In fact, teacher educators are concerned about teachers' anti-intellectualism, as most teachers stay at their comfort zone and resistant against complex higher order thinking. This case study is an attempt to showcase how to enhance teachers' intellectual growth in the university classrooms. Using Valli's typology of reflections, this study first identifies what level of reflections teachers engage, and documents what attempts I, as a teacher educator, made to promote higher order thinking. The finding confirms the existing literature that teachers tend to engage in pragmatic/practical thinking, and are not ready, or not willing, to take up a deeper level of intellectual reflections. My efforts to cultivate a culture of inquiry became unsuccessful, because teachers' practicality-oriented mindset conflicts with my goal of promoting nonpragmatic inquiry, i.e., higher order thinking. This study leaves an implication for teacher educators: Teacher education curriculum oughts to undergo a paradigmatic change from pragmatic inquiry into non-pragmatic inquiry to allow teachers beyond the normative framework, and nourish teachers' intellectual life.
\end{abstract}

Keywords: teaching, teachers, high-level, case study

\section{Introduction}

In Educational Researcher in 2003, David Labaree made a rightly yet disheartening claim about teacher culture that teacher culture is characterized as practicality oriented, limited to normative thinking, and anti-intellectual. Labaree's critique of teacher culture goes on to state that teachers who assess, evaluate, and judge others in daily life lack reflective capacity that would lead them to self inspection or critical thinking. Much literature from Western countries report that teachers are trained to act according to the prescriptive way, rather than trained to be inquirer or thinker (Manzuk,1997; McLaughlin \& Black-Hawkins, 2004). Christianakis (2010) echoes this argument, observing that teachers are not particularly trained to engage in intellectual work (e.g., reflecting) and their intelligent disposition is hardly rewarded in K-12 setting in the U.S. My experiences as a teacher educator who teaches K-12 teachers in the U.S. coincide with the above assertions. I have constantly grappled with how to get teachers engaged in higher order thinking, e.g., critical thinking.

As a teacher educator, I developed a course whose objective was to enhance teachers' intellectual capacity and their personal intellectual growth. The teacher education literature has focused on teachers' reflection only in relation to their professional growth and self-efficacy growth (e.g., Jaeger, 2013; Jaeger, 2013; Kelly, 2004; Yost, 2000; Kiss \& Townsend, 2012).However, very few focus on teacher's personal intellectual growth. Nelsen (2015) asserts that teachers' genuine inquiry that seeks growth should be encouraged among teachers. In other words, teachers have to be intellectual agents, and be able to grow such capacity through their career. While a majority of the teacher education literature have discussed teacher reflection as a means of better teaching or better decision-making, my premise is based on reflection as an end, i.e., reflection for reflection's sake.

This research emerged out of my desire to improve my teaching in reaching the goal of enhancing the capacity of higher order thinking. I carefully selected course materials with that goal in mind. Specifically, I stayed away from practical resources, because most practical resources provide only a quick fix instead of leading teachers into deep reflections. All required assignments were designed with the aim to lead my students into high order inquiry. This research launched when I started documenting my teaching experiences. First, I did a literature review on teacher reflection, which will be presented in the following section. The typology of reflection will provide a tool for data analysis. 


\section{Literature Review and Theoretical Framework}

Many teacher education programs have reacted to Labaree's lament about teacher's anti-intellectualism, and have strived to develop inquiry-based programs emphasizing reflection among teachers (e.g., Fox, White, \& Kidd, 2011; Valli, et al 2006). During the past decades, reflective practice has been incorporated into the mission of many teacher education programs. The importance of reflective habit among teachers has been discussed extensively since Schon's seminal book, The Reflective Practitioner (1983), and was taken up by several key educational researchers (Fendler, 2003; Zeichner \& Liston, 1996; Valli, 1997). The discussion of the reflective teachers is currently situated within the discourse of disposition in teacher education. University-based teacher educators grapple with questions such as: what is the effective way of developing systematic reflections beyond mere rumination? To what extent can the university help enhance teachers' reflective skills? How do teacher educators engage teachers in self-reflective thinking? A variety of activities have been proposed as a way to promote teachers' inquiry such as journal entry, dialogic journal writing (Lee, 2004), portfolio (Fox, White, \& Kidd, 2011) and video taping, and action research (Liston \& Zeichner, 1990).

There is, however, little agreement in the teacher education literature as to what exactly reflection entails (Clara, 2015; Rodgers, 2002; Valli, 1997). Not all reflections are the same quality. Rogers (2002) differentiates systematic reflection from merely ruminating. Several researchers develop typologies of reflection by exploring what kinds of reflection teachers are engaged .Linda Valli (1997) advanced Schon's claim about teacher reflection, and developed a typology of reflection: technical reflection, deliberative reflection, reflection-in-action, reflection-on-action, personalistic reflection, and critical reflection. Jay and Johnson (2002) have developed a similar typology as Valli's, and came up with three types of reflection: descriptive, comparative and critical reflection. Jay and Johnson's research (2002) also shows how the typology is used to guide teachers' reflection in a teacher education program. Reflection typology is used to analyze the level and quality of reflection, and further used as a tool to guide deeper reflections (Luttenberg \& Bergen, 2009; Minott, 2008).

Although the typologies are not meant to be hierarchical, it is agreed that Schon's 'technical rationality,' Valli's 'technical reflection' are not intellectual in nature. Teacher educators' goal is to move beyond technical reflection and teach higher levels of reflection such as deliberative reflection, personalistic reflection, and critical reflection. As argued by Labaree (2003), teacher educators deal with anti-intellectualism as most teachers stay at their comfort zone of technical reflections. This case study is an attempt to showcase how to enhance teachers' thinking in the university classroom.

In order to better serve my data, I reclassified Valli's (1997) typology into two groups: pragmatic reflection and nonpragmatic reflection. Although Valli did not use the concept, pragmatic reflection, I reconstructed Valli's typology in the way to make a distinction between pragmatic and non-pragmatic reflections. Valli (1997)'s "technical reflection" as the lowest form of reflection, is categorized as pragmatic reflection because such reflection occurs when it has a pragmatic purpose: to resolve a problem. Strictly speaking, technical reflection is not even reflection, because Valli states that technical reflection is when "teachers judge their own teaching performance on the basis of external imposed criteria" (p. 75). Most teachers adopt a prescriptive way to learn how to teach. They base their judgment on outside authorities who set the standards, guidelines, and evaluation criteria, instead of on their own thinking. Deliberative reflection, according to Valli, occurs when teachers use multiple resources in order to make a best decision, or/and to find a best solution. Unlike technical reflection, deliberative reflection, in nature, is intelligent because thinking on one's own is involved. The goal of deliberative reflection is to solve a problem with a variety of sources, e.g., research, experiences, advice.

What is non-pragmatic reflection among Valli's typology are personalistic reflection and critical reflection has no pragmatic goal. Valli defines personalistic reflection as reflecting on what type of person they want to be, and how being a teacher helps them accomplish their life goal. Critical reflection views school and knowledge as a political construction, especially power relations. Critical reflection is inevitably connected with the social justice literature (Hytten, K., \& Bettez, 2011), which is an important disposition in current teacher education missions (Villegas, 2007). These two reflections have little pragmatic goal, therefore intellectual in nature. Unlike a majority of educators who see the purpose of teachers' reflection as a means of high test scores, nonutilitrian reflections such as personalistic and critical reflections focus on developing intelligent habits and intelligent dispositions among teachers. These non-pragmatic reflections are akin to Dewey's (1934) concept of reflection, as Dewey claimed that reflection occurs in order to grow, with no external purpose. Related is Nelsen's (2015) argument that the teacher education program should promote genuine inquiry seeking growth and the development of new habits.

Valli's typology provides a useful tool for teacher educators who are charged with nurturing intelligent disposition among teachers. Many university-based teacher educators, indeed, report challenges in guiding teacher's reflection beyond classroom management concerns (Mandzuk, 1997). Some complain of lack of consistency in assessing the quality of reflection (Dyment, J. E., \& O'Connell 2011; Rodgers, 2002). Valli's typology is significant in this context. My goal as a teacher educator was to promote intelligent dispositions, the kind of intelligence required beyond teachers' immediate classroom concerns. This self study reports my such attempt. 


\section{Methodology}

I adopted a case study model as a methodology of this study. The case is defined as one semester's teaching experience that I had at a university's teacher education program. I documented my journey of teaching, collecting lesson plans, course materials, reflective notes, email correspondences with my students. As it is an analysis of my own teaching, this case study is blended into a self study. The course that this research centered on is, Issues in Urban Education, offered in Fall 2016.The course was part of Ed.D degree requirements, and was enrolled with four doctoral students in Fall 2016. All four students were classroom teachers in the public K-12 system.

I required weekly journaling to all four students, and the class discussed each student's journal entry to share our related experiences and perspectives. Each student picked their own interest and problem as a topic of their journal entry, and chronicled the events around the selected topic in order to delve deeply into the problem. The purpose of the assignment was to promote teachers' inquiry habit shown in writing and in debriefing. All four students chose a problem that they encountered as a teacher in their own classroom. Two picked discipline and classroom management issues; another picked a topic of instructional method, as she was struggling to identify an effective pedagogy. Another student picked an administrative problem. Among the student journals, I focus on Richard (pseudonym) for this research. The class discussions on Richard's journal entry were the most lively and animated, as fellow classmates related to the issue. Also, Richard's journal entry and ensuing debriefing discussions enlightened my insights into how I could have done differently. Richard (pseudonym) had given me permission to use his journal for my self-study research. The institutional Review Board approved my study by considering this study as an exempt category.

Central to the data source is not Richard's journal itself, but my teaching of the class discussions on Richard's journal. This study documents my struggling story of teaching the class higher order thinking. While I was engaged in the discussion as a facilitator, I paid attention to how I was or was not able to help the class further their thinking process. Therefore, the study necessarily adopts a self study. As Dinkelman (2003) argues, a self study is used for teacher educators to model reflective teaching to their students. My self study is designed for the purpose of reflecting myself as a teacher educator, specifically how successfully I helped teachers (my students) grow their intellectual capacity to the level of nonpragmatic inquiry such as critical reflection. Data analysis centered around my research question: What did I do to promote high level thinking? Data analysis follows chronological analysis, focusing on what happened in discussion sessions, paying attention to what attempts I made to enhance students' inquiry.

\section{Data Analysis and Findings}

\subsection{Richard as Teacher}

Richard is a kindergarten teacher, in his third year into the teaching profession. Richard's inquiry journey is prompted by one problem student, named AJ (pseudonym). AJ was a particularly difficult student. He threw tantrums to Richard, and refused to follow Richard's instructions. Richard, as a relatively novice teacher, had a hard time handling AJ.Richard provided an in-depth account of his daily struggle with AJ, describing each day's incident along with his reflection on it. The narrative recounts each episode of Richard's disciplinary tactic (e.g., give incentive for good behavior, use the rewardpunishment system, rely on social worker and principal, case manager, and assistant superintendent, threaten to call mom). Richard described his emotional frustrations about his own inability to employ an effective disciplinary method.

Richard chronicled his various attempts from positive reinforcement such as praise, encouragement, giving incentive, to punishment or to threatening to call his mom. His entry reads,

The student was given a task. The task called for the student to sit and use a wipe off board in order to practice writing the word of the week. When I left him alone, he became easily frustrated. With his frustration, he said, "I can't do this, and went over to grab blocks to play with. I went over to the student and calmly said, "You can do this", and took the blocks away and guided him back to his seat. I sat next to him, and he threw a tantrum about it. I instructed a child in his group to help him and then I walked away. He was not able to finish the task, during his writing center.

As is shown above, Richard started with positive reinforcements to AJ, but his 'nice' approach did not always work. As AJ's misbehavior got intense, Richard used more aggressive interventions such as minimizing outdoor recess time and even threatening to call his mom. The diary reads, "He threw the book and said, 'I don't want to read this, this is stupid."' Richard's last resort was threatening to AJ to call his mom. He stated in his diary, "I told him that I was going to have to write a note to his mother about his behavior and he stopped and looked at me and said, NO! He walked himself over to finish his journal." Richard sometimes tried to negotiate with AJ by saying "You will be able to play with the blocks when you are able to go over the seasons of the year with me." Despite multiple kinds of efforts, AJ's behavior remained unchanged, and only interfered Richard's instruction. Richard thought that his behavior disadvantaged other students' learning, and came to believe that it would be more beneficial to remove AJ from his class. 
Richard then started relying on outside resources such as case manager, psychologist, assistant supervisor. In a debriefing session, Richard stated that he spent a significant amount of time with AJ before he sought outside-classroom resources. The below vignette shows how he delegated to a school psychologist:

A.J. was running around the classroom with another child while the rest of the class was told to work on their journal. He decided that he was going to throw his book in the middle of the classroom and refuse to work. I tried to bribe him with a toy, but he did not want to do it. I had to contact the school psychologist to help me get him settle. She took him for ten minutes to work on his behavior. They came back in and he apologized.

The decision of seeking outside resources was not particularly for AJ, but more for Richard's and the whole class's benefit.

When Richard shared his journal entry with me, the class showed an enormous amount of sympathy in Richard's attempt to contact the school psychologist. Every single classmate related, saying that they experienced this type of students, and reached a consensus that this type of student is out of teacher's capacity. The class actively contributed to the discussions about what outside resources are available in their respective school.

While the class engaged in a heated discussion on various intervention strategies, I noticed helplessness and disempowerment among teachers. They seemed to conclude that all resources had been exhausted, and therefore this issue should be dealt with outside of the teacher's power. Richard and his classmates affirmed each other, therefore, in their perspectives of having to resort to the principal or social worker. I pondered: what kind of intellectual growth do they achieve? I am less interested in whether Richard's action (i.e., removing AJ) was the right one, than what kind of inquiry has led Richard to come to the decision.

\subsection{Me as Teacher Educator: Facilitation 1}

I intervened the class discussions whenever I detected a sign of Vallis' 'technical reflections.' My efforts did not yield the intended outcome, i.e., advancing the level of teachers' thinking. The definition of professional support differ between me and my students: Mine is to empower students by promoting non-pragmatic reflections, but my students' expectation was me giving off the solution.

My focus was not about how to help Richard find a magically effective disciplinary solution. I instead challenged the very question that Richard posed, i.e., how can I fix AJ's behavior? or how can I make class undistracting? While Richard and his classmates engaged in a pragmatic inquiry trying to solve their teacherly problem, I tried to turn it into nonpragmatic inquiry and tried to use this incident as a tool for their personal growth. My job was to create what Dewey calls a 'disequilibrium' that constitutes a new need in the intellectual community (Nelsen, 2015).

I was troubled by the anti-intellectual nature of inquiry shown among the teachers' remarks. I strategically attempted to stop their conversation where they were in the middle of discussing on how to remedy AJ's problem, and I suggested, "Let's focus on AJ, hold off on discussing how to fix AJ." In Richard's diary is there lack of focus on the student (AJ) as a whole person. When class read his diary, no one asked about who AJ was. Could they have asked some questions about AJ's family, his prior experience, or strength? While their brainstorming revolved around the theme of behavior modification strategies, and how to control AJ, a genuine concern or caring about AJ was conspicuously missing. Richard's journal omits the information about AJ's family background, ethnic/class background, or his prior experience possibly leading to his current state. Only when asked, Richard mentioned that AJ is a Hispanic, from working class family, but failed to link his behavior with the context of larger socio-cultural politics.

Richard was apparently more concerned about the classroom management than caring for AJ, which is shown in the following excerpt: "Today, A.J. was taken out during the morning to work in a small group with a basic skills instructor. The students were uninterrupted and worked well." Richard said in sigh that he sympathized but literally had no time to devote his instructional time just to one student. Richard's decision to remove AJ comes from his valuing the whole group over AJ.

I posed a question, "what is your goal as a teacher?" I pondered, was he trying to be an effective teacher for academic achievement, or successful classroom manager, or caring teacher? or all of these? This question hopefully would allow Richard to be able to examine his own beliefs or value system. Such self-reflective questions fit what Valli's calls 'personalistic reflection' where teachers examine their own personal identity (Valli, 1997). Personalistic inquiry is non-pragmatic in nature. I managed to shift the focus away from anti-intellectual pragmatic to non-pragmatic inquiry.

Richard and his classmates seemed to be pondering about my question of what was the goal as a teacher. Richard himself was not able to formulate his answer right away. He said that he wish he could be both caring teacher and effective teacher, but don't know how. Another student turned back to me asking me "Dr.X (referring to me), Should I have taken care of this type of student, instead of caring about the rest of the students in my class? Do I have to focus on one student, sacrificing the whole class?" These questions helped me identify the level of their reflection and indicate students' discomfort with non-pragmatic inquiry. They expected me to answer the what-do-I do question. My push for non- 
pragmatic inquiry became a dead-end. This experience confirms other researcher's finding that the teachers who get used to pragmatic inquiry tend to expect the teacher educator to offer a solution to their problem.

\subsection{Me as Teacher Education: Facilitation 2}

The second session was somewhat successful, because my goal was to help teachers expand the framework of instructional philosophy. I noticed that Richard seemed obsessed with his goal of being orderly and having a tight rein. I realized that his inflexibility result in blaming others, instead of self-introspective reflection. I paused at the following.

During writing, A.J. was not able to tell me the seasons of the year. He was getting frustrated, so he went to the blocks saying, "All I want to do is play". I went over to A.S. and said, "You will be able to play with the blocks when you are able to go over the seasons of the year with me. I have a book that we could use to help us". He said, "alright". We went over to the carpet and he opened the book. I helped him look for the page that has the seasons. I asked him, "How many seasons are there?" He answered, "I don't want to do this." He got up and ran around the room. I went to get him and said once again as I lowered myself to his eye level, "You can play when you are done telling me the seasons". I was able to get him to tell me how many seasons, their names, and what happens during that seasons based on the pictures he saw.

As shown above, Richard was stubborn in his own plan of instruction. He did not tolerate AJ's disobedience, as it is deviant from his direction. Despite AJ's insistence of playing with blocks, Richard goaded AJ to read first, and made AJ eventually follow Richard's instruction. Another example below shows the similar tendency, and resulted in power struggles between the two:

Today's lesson was to teach them more or less from 1-5. 5 minutes into the lesson, A.J. got up from his chair and started to run around the room. I told him once to sit back down and pay attention to the lesson. He would not sit. Instead, he went to get a puzzle that he is comfortable with and sat down to play. I took it away from him and he started to scream.

In a debriefing session, where we discussed the above, I highlighted these excerpts in class. Several classmates of Richard's showed deep sympathy with Richard. Richard reflected on his decision regrettably, and commented that he should have given AJ a choice. Although he felt bad about his decision, he didn't seem to be knowledgeable about possible alternatives, competing paradigms of instructional philosophy or pedagogical strategy.

I noticed that the lack of his pedagogical knowledge base prevented him from engaging in Valli's deliberative reflection. In interpreting AJ's resistance, Richard was stuck in a normative framework, seeing AJ as deviant. What he overlooked was Richard's own instructional style. I decided to introduce learner-centered pedagogy as an alternative instructional/disciplinary strategy. In learner-centered pedagogy where learning happens from the learner's own interest, teachers are not concerned about being orderly. Richard's teacher-directed instruction rendered AJ as deviant student, and made it impossible for AJ to be a good student. The learner-centered pedagogy perspective would conceptualize AJ as an excellent learner, learning from playing with puzzle. Richard's initial focus on controlling class is modified with a new framework of learner-centered education, where teachers focus on how to help each other learn, how to motivate the class, and how to use each student's strengths.

My goal was to expand the repertoire of knowledge from which their deliberation takes place. This deliberative reflection, unlike technical reflection, is intellectual reflection because it engages active thinking, deliberative thinking in nature. Deliberative reflection is categorized as pragmatic reflection with a clear purpose of reflection: to find a best pedagogy or make a best decision.

My instruction about student-centered instruction elicited highly positive reactions among my students. Richard nodded, and agreed on the principle of student-centered pedagogy. He said he should have given more choices to AJ and will adopt student-centered pedagogy in his teaching practice. Another student affirmed the importance of student-centered pedagogy, and thanked me for reminding her of this pedagogy. All students seemed appreciative of my guidance, felt empowered being equipped with useful information to use when similar situation occurs. This reaction starkly contrasts with when I initiated non-pragmatic reflections described in "Facilitation 1." I believed that positive reactions from my students indicate that students are comfortable with pragmatic reflection, with a goal of solving pedagogical problems. The next episode, "facilitation 3" confirms this conclusion.

\subsection{Me as Teacher Educator: Facilitation 3}

The third attempt was a total disaster, as I opened up critical-oriented questions drawn from the social justice literature. The reactions were one of resistance, confusion, and befuddled. I tried to develop the ability in which my students see the underlying assumptions of schooling in relation to power relations. I noticed that Richard' journal was mostly about factual descriptions on $\mathrm{AJ}$, and about self evaluation of whether his decision was right or wrong. I had an intention to raise a more thought-provoking question, which would push him to re-examine his own belief, bias, or perspective. I 
posed: Would it be possible that something about the teacher contributes to AJ's behavior? In preparation to a debriefing session, I assigned one article, one by Wood that points to how teacher's bias influenced student' behavior (Wood, 2008). Wood's research (2008) shows how much the teacher's bias and stereotype contributes to defining a certain student as "misbehaving" ones, and how much the students were hurt and came away with anger. When we discussed this article in class, I made a disclaimer that I did not mean to say that Richard had a bias to label AJ.

Wood's research (2008) invited us to important questions: Are our gaze, lens, perspective, judgment truly unbiased or neutral? How is misbehaving defined? How do we define learning disability or attention deficit? Who defines the rule and policy? To whose benefit does the separation structure of resource teacher work? What is the philosophical assumption of the resource structure within school? Wood's research helped us bring up foundational discussion of whether a school norm is unfairly employed for a certain subculture. I was hoping that our discussion would touch upon multiple layers of social, cultural, ideological contexts behind AJ's behavior. I was hoping that the discussion would liberate Richard and others who tend to think within their comfort zone and never questions a normalized notion of 'standard' and 'norm.'

To my dismay, students' initial reaction was one of denial. Richard said in response to Wood's article that he did not treat $\mathrm{AJ}$ with a bias. I pushed further and asked him, did AJ always misbehave? Have you ever noticed that $\mathrm{AJ}$ followed his instruction? Richard's portrayal of AJ as a disruptive student could be a sign of his own bias, for nowhere in this diary was AJ's good behavior described. I challenged Richard by suggesting that his own bias (or even his labeling) might have led him to portray only misbehaving moments. Richard bashfully nodded.

Introducing a critical lens on education was, indeed, the most challenging task for me. Whenever I attempted to discuss power relations in social/cultural, and interpersonal context where a norm is situated, I met with puzzlement or resistance. One student defiantly refuted: "How can we change the school structure? I am not an administrator." When I posed a nonpragmatic question, they retorted with a pragmatic question: "I am not an administrator. What can I do?" They seemed unable to see their problem beyond the classroom wall, resist to open up to genuine inquiry that would potentially expand their intellectual capacity. Lack of genuine inquiry prevented them from seeing themselves within large education communities and from seeing themselves as change agents. Nelsen (2015) argued that teacher educators "do not just help students reflect on their discrete actions within a specific context but to do so as members of education communities that embrace genuine inquiry seeking growth and the development of new habits" (p. 94). In my experience, my students' old habit of doing a pragmatic inquiry makes it hard for me to move beyond a normative framework and move toward a change agent. Much education researchers find critical reflection as a necessary step of becoming an empowering progressive leader. For example, Lupinski (2012) whose research on reflective practitioners in HBCU emphasizes the transformative practitioner as a necessary characteristics of reflective practitioners. My experience led me to conclude that teachers are more willing to do pragmatic thinking, and are not ready, or not willing, to take up a deeper level of intellectual reflection driven by their own curiosity. A culture of inquiry is remote among my students.

\section{Implications for Teacher Educators}

My experience confirms earlier assertions about teacher culre: Teachers tend to have practice -oriented mindset, lacking intellectualism. My data shows that the teachers have a propensity for pragmatic inquiry for the purpose of problemsolving. My students were curious about alternative discipline strategies (Facilitation 2), but they resisted against nonpragmatic inquiry (Facilitations 1 and 3). I struggled in developing a new habit among teachers who would question the fundamental moral structure around schooling. I attempted to help them position themselves beyond the classroom wall, but my attempt was not successful.

My experience shows that the lack of genuine inquiry limits themselves to the confines of 'how-to' manuals, and deters transformative thinking. In order to get them out of the normative framework, I tried to help them discover a new self by asking questions such as 'who they are,' how they are implicated within this society,' 'where they are positioned vis-a-vis their students,' and 'what is their goal as a teacher.' There is a need for a teacher education curriculum that will present a new vision toward nourishing nonpragmatic inquiry. If teacher inquiry revolves around solving an immediate problem and fails to tackle deeper issues, such inquiry would not serve much to expand the intellectual capacity.

My journey of teaching high level thinking to teachers ended in failure, because, I believe, the course work in teacher education is not aligned with high order thinking. What is more troubling as a teacher educator is the resistance against critical reflections. Lack of critical reflections shapes a particular disposition, as it feeds the deficit thinking where teachers view low income minority students as deficit or deviant from the norm (Villegas, 2007). Teaching high level thinking to teachers involves a paradigm shift in teacher education curriculum. Having teachers conduct action research does not sufficiently accomplish the goal of developing deeper reflection, as such research is often constrained within a normative framework unless someone guides their inquiry to non-pragmatic dimension. I believe that foundations courses and infusion of liberal arts curriculum would be an essential ingredient to non-pragmatic thinking. Social foundation in teacher education programs should be incorporated to promote critical disposition (Bustin2005;Kerr, Mandzuk, \& Raptis, 2011). 


\section{References}

Bullough, R. (2008). Teaching and reconsidering the social foundations of education: A self study. Studying Teacher Education, 4(1), 5-15. https://doi.org/10.1080/17425960801976206

Bustin, D. W. (2005). How social foundations of education matters in teacher preparation: A policy brief. Educational Studies, 38, 214-229.https://doi.org/10.1207/s15326993es3803_2

Clara, M. (2015). What is reflection? Looking for clarity in an ambiguous notion. Journal of Teacher Education, 66(3), 261-271. https://doi.org/10.1177/0022487114552028

Cochran-Smith, M., \& Lytle, S. L. (1999). The teacher research movement: A decade later. Educational Researcher, 28(7), 15-25. https://doi.org/10.3102/0013189X028007015

Dinkelman, T. (2003). Self-study in teacher education: A means and ends tool for promoting reflective teaching. Journal of teacher education, 54(1), 6-18. https://doi.org/10.1177/0022487102238654

Dyment, J. E., \& O'Connell, T. S. (2011). Assessing the quality of reflection in student journals: A review of the research. Teaching in Higher Education, 16(1), 81-97. https://doi.org/10.1080/13562517.2010.507308

Fendler, L. (2003). Teacher reflection in a hall of mirrors: Historical influences and political reverberations. Educational researcher, 32(3), 16-2. https://doi.org/10.3102/0013189X032003016

Fox, R. K., White, C. S., \& Kidd, J. K. (2011). Program portfolios: Documenting teachers' growth in reflection-based inquiry. Teachers and teaching: Theory and practice, 17(1), 149-167. https://doi.org/10.1080/13540602.2011.538506

Hytten, K., \& Bettez, S. C. (2011). Understanding Education for Social Justice. Educational Foundations, $25,7-24$.

Jaeger, E. L. (2013). Teacher reflection: Supports, barriers, and results. Issues in Teacher Education, $22(1), 89$.

Jay, J. K., \& Johnson, K. L. (2002). Capturing complexity: A typology of reflective practice for teacher education. Teaching and Teacher Education 18, 73-85. https://doi.org/10.1016/S0742-051X(01)00051-8

Kerr, D., Mandzuk, D., \&Raptis, H. (2011). The Role of the Social Foundations of Education in Programs of Teacher Preparation in Canada. Canadian Journal of Education, 34(4), 118-134.

Kiss, K. L., \& Townsend, J. S. (2012). Teacher inquiry: From knowledge to knowledges. Issues in Teacher Education, 21(2), 23-35.

Klehr, M. (2012). Qualitative teacher research and the complexity of classroom context. Theory into Practice, 51, 122128. https://doi.org/10.1080/00405841.2012.662867

Labaree, D. (2003). The peculiar problems of preparing educational researcher. Educational researcher, 32(4), 13-22. https://doi.org/10.3102/0013189X032004013

Lee, H. J. (2005). Understanding and assessing preservice teachers' reflective thinking. Teaching and Teacher Education, 21(6), 699-715. https://doi.org/10.1016/j.tate.2005.05.007

Lee, I. (2004). Using dialogue journals as a multi-purpose tool for preservice teacher preparation: How effective is it?. Teacher Education Quarterly, 31(3), 73-97.

Liston, D. P., \& Zeichner, K. M. (1990). Reflective teaching and action research in preservice teacher education. Journal of Education for Teaching, 16(3), 235-254. https://doi.org/10.1080/0260747900160304

Lupinski, K., Jenkins, P., Beard, A., \& Jones, L. (2012). Reflective Practice in Teacher Education Programs at a HBCU. Educational Foundations, 26, 81-92.

Luttenberg, J., \& Bergen, T. (2008). Teacher reflection: the development of a typology. Teachers and teaching, 14(5-6), 543-566. https://doi.org/10.1080/13540600802583713

Lytle, S., \& Cochran-Smith, M. (1992). Teacher research as a way of knowing. Harvard Educational Review, 62(4), 447475 .

Mandzuk, D. (1997). A doctoral graduate's return to the elementary classroom: An example of sociological ambivalence. Teaching and Teacher Education, 13(4), 439-449. https://doi.org/10.1016/S0742-051X(96)00041-8

McLaughlin, C., \& Black-Hawkins, K. (2004). A schools-university research partnership: Understandings, models and complexities. Journal of in-service education, 30(2), 265-284. https://doi.org/10.1080/13674580400200319

Nelsen, P. J. (2015). Intelligent dispositions: Dewey, habits and inquiry in teacher education. Journal of Teacher Education, 66(1), 86-97. https://doi.org/10.1177/0022487114535267 
Noffke, S. (1997). Professional, personal, and political dimensions of action research. Review of Research in Education, 22, 305-343. https://doi.org/10.2307/1167378

Rodgers, C. (2002). Defining reflection: Another look at John Dewey and reflective thinking. Teachers College Record, 104(4), 842-866. https://doi.org/10.1111/1467-9620.00181

Schon, D. A. (1984). The reflective practitioner: How professionals think in action (Vol. 5126). Basic books.

Schulz, R., \& Hall, C. (2004). Difficulties in promoting inquiry in teacher education partnerships: English and Canadian perspectives. Journal of Education for Teaching, 30(3), 255-269. https://doi.org/10.1080/0260747042000309484

Spalding, E., Wilson, A., \& Mewborn, D. (2002). Demystifying reflection: A study of pedagogical strategies that encourage reflective journal writing. Teachers College Record, 104(7), 1393-1421. https://doi.org/10.1111/14679620.00208

Stevenson, H. J., \& Cain, K. J. (2013). Talking to paper doesn't work: factors that facilitate preservice teacher reflection. Teacher Education Quarterly, 40(2), 75-88.

Valli, L, van Zee, E. H., Rennert-Ariev, P., Mikeska, J., Catlett-Muhammad, S., \& Roy, P. (2006). Initiating and sustaining a culture of inquiry in a teacher leadership program. Teacher Education Quarterly, 33(3), 97-114.

Valli, L. (1997). Listening to other voices: A description of teacher reflection in the United States. Peabody Journal of Education, 72(1), 67-88. https://doi.org/10.1207/s15327930pje7201_4

Villegas, A. M. (2007). Dispositions in teacher education: A look at social justice. Journal of Teacher Education, 58(5), 370-380. https://doi.org/10.1177/0022487107308419

Westheimer, J., \& Kahne, J. (2004). What kind of citizen? The politics of educating for democracy. American educational research journal, 41(2), 237-269. https://doi.org/10.3102/00028312041002237

Woods, R. (2008). When rewards and sanctions fail: A case study of a primary school rule-breaker. International Journal of Qualitative Studies in Education, 21(2), 181-196. https://doi.org/10.1080/09518390701868979

Yost, D. S. (2006). Reflection and self-efficacy: Enhancing the retention of qualified teachers from a teacher education perspective. Teacher Education Quarterly, 33(4), 59-76. https://doi.org/10.1177/002248710005100105

Yost, D. S., Sentner, S. M., \& Forlenza-Bailey, A. (2000). An examination of the construct of critical reflection: Implications for teacher education programming in the 21 st century. Journal of Teacher Education, 51, 39-49.

Zeichner, K., \& Liston, D. (1987). Teaching student teachers to reflect. Harvard Educational Review, 57(1), 23-49. https://doi.org/10.17763/haer.57.1.j18v7162275t1w3w

\section{Copyrights}

Copyright for this article is retained by the author(s), with first publication rights granted to the journal.

This is an open-access article distributed under the terms and conditions of the Creative Commons Attribution license which permits unrestricted use, distribution, and reproduction in any medium, provided the original work is properly cited. 